\title{
Psychological, interpersonal, and clinical factors predicting time spent on physical activity among Mexican patients with hypertension
}

\author{
José Luis Ybarra Sagarduy' \\ Dacia Yurima Camacho \\ Mata' \\ José Moral de la Rubia ${ }^{2}$ \\ Julio Alfonso Piña López ${ }^{3}$ \\ José Luis Masud Yunes

\section{Zárraga $^{4}$}

'Unit of Social Work and Human Development, Autonomous University of Tamaulipas, Ciudad Victoria, ${ }^{2}$ School of Psychology, Autonomous University of Nuevo Leon, Monterrey, ${ }^{3}$ Independent Researcher, Hermosillo, ${ }^{4}$ Institute of Health and Safety Services for State Workers, Clinic for the Study and Prevention of the Chilhood Obesity, Ciudad Victoria, Mexico
This article was published in the following Dove Press journal: Patient Preference and Adherence

\begin{abstract}
Background: It is widely known that physical activity is the key to the optimal management and clinical control of hypertension.

Purpose: This research was conducted to identify factors that can predict the time spent on physical activity among Mexican adults with hypertension.

Methods: This cross-sectional study was conducted among 182 Mexican patients with hypertension, who completed a set of self-administered questionnaires related to personality, social support, and medical adherence and health care behaviors, body mass index, and time since the disease diagnosis. Several path analyses were performed in order to test the predictors of the study behavior.
\end{abstract}

Results: Lower tolerance to frustration, more tolerance to ambiguity, more effective social support, and less time since the disease diagnosis predicted more time spent on physical activity, accounting for $13.3 \%$ of the total variance. The final model shows a good fit to the sample data $\left(p_{B S}=0.235, \chi^{2} / g l=1.519\right.$, Jöreskog and Sörbom's Goodness of Fit Index $=0.987$, adjusted modality $=0.962$, Bollen's Incremental Fit Index $=0.981$, Bentler-Bonett Normed Fit Index $=0.946$, standardized root mean square residual $=0.053$ ).

Conclusion: The performance of physical activity in patients with hypertension depends on a complex set of interactions between personal, interpersonal, and clinical variables. Understanding how these factors interact might enhance the design of interdisciplinary intervention programs so that quality of life of patients with hypertension improves and they might be able to manage and control their disease well.

Keywords: physical activity, hypertension, personality, social support, time since diagnosis, intervention programs

\section{Introduction}

In 2012, the National Health and Nutrition Survey (NHNS) conducted prevalence analysis of hypertension in Mexico by administering a sample questionnaire to 8,412 adults in the age group of 20 years and above. Their results showed a high prevalence of hypertension, equivalent to $25.5 \%$ of the total population. Of this subsample, $58.7 \%$ reported an inadequate control of the disease. ${ }^{1}$ To deliver high-quality services for patients with hypertension and other chronic non-communicable diseases in Mexico (including diabetes and other cardiovascular diseases), extensive collaborative and integrated health care efforts are necessary. First, we need to understand the role played by several factors (biological, psychological, and interpersonal) to develop and implement the best strategies and to improve the management and clinical control of the disease.
Correspondence: José Luis Ybarra Sagarduy

Unit of Social Work and Human Development, Autonomous University of Tamaulipas, University Center "Adolfo López Mateos”, Ciudad Victoria 87000,

Tamaulipas, Mexico

Tel +528343181800

Email jsagarduy@gmail.com 
According to health care personnel, two of these factors are related to psychological and interpersonal skills, which can negatively affect the practice of treatment-adherence and health care behaviors (taking medication, measuring blood pressure, maintaining a balanced diet, and primarily performing physical exercise). ${ }^{2-4}$ Regular physical exercise is highly recommended to patients with hypertension in order to maintain a good health as it has been proven to improve the function of the heart while reducing the risks of other diseases (eg, cystic fibrosis and heart failure) ${ }^{5,6}$

Previous research conducted on adults in the age group of 20 years and above have demonstrated the psychological and interpersonal benefits of physical exercise (aerobic and non-aerobic), including, among others, a feeling of psychological well-being (experiencing good mood), perceived competency, self-efficacy, high motivational levels, less perceived stress, and a better perception of social support. ${ }^{7-9}$ To understand the role of both psychological factors and interpersonal skills among patients living with chronic disease, a psychological model for the investigation of treatment-adherence and health care behaviors has been previously proposed (Figure 1). This model shows the interactions of the aforementioned factors in four phases. In Phase 1 of this model, personality is the key factor that influences both the aforementioned behaviors. ${ }^{10}$ Personality defines the consistent ways in which a person behaves accordingly as they have done in the past, when they face the following situations: 1) they cannot predict the consequences of stimulus after their behavior, a phenomenon known as "unpredictability";
2) there are stimuli signals that are experienced ambiguously, a phenomenon known as "ambiguity"; 3) when behaving, stimulus consequences are obtained that are not dependent on what the subject does, a phenomenon known as "uncertainty". ${ }^{11}$ In addition, Phase 1 of this model has two more variables: the motives underlying each behavior (why things are done) and behavioral competencies (what patients know about a disease and what they know about how to treat it effectively). Phase 2 of the psychological model includes a chronic disease (and other conditions), and Phase 3 of the psychological model includes two types of behaviors: those associated with treatment-adherence and those associated with the disease. Phase 4 of the psychological model includes clinical and health outcomes.

In this theoretical model, it is proposed that, as in the case of hypertension, the psychological variables of Phase 1 (personality, motives, and behavioral competencies) will make the practice of adherence or health care behaviors in Phase 3 more or less probable. This can also be affected by the disease-related behaviors (eg, anger, impulsivity, anxiety, and depression). If adherence and health care behaviors are put into play, a person with hypertension is expected to obtain optimal health outcomes (blood pressure control) in Phase 4 of this model, which in turn, will make the occurrence of other, more negative outcomes, less possible (eg, dyslipidemia and congestive heart failure). Social support has recently been included as an exogenous variable in the model, which has contributed to the analysis of treatment-adherence and health care behaviors in people living with HIV infection. ${ }^{12-14}$

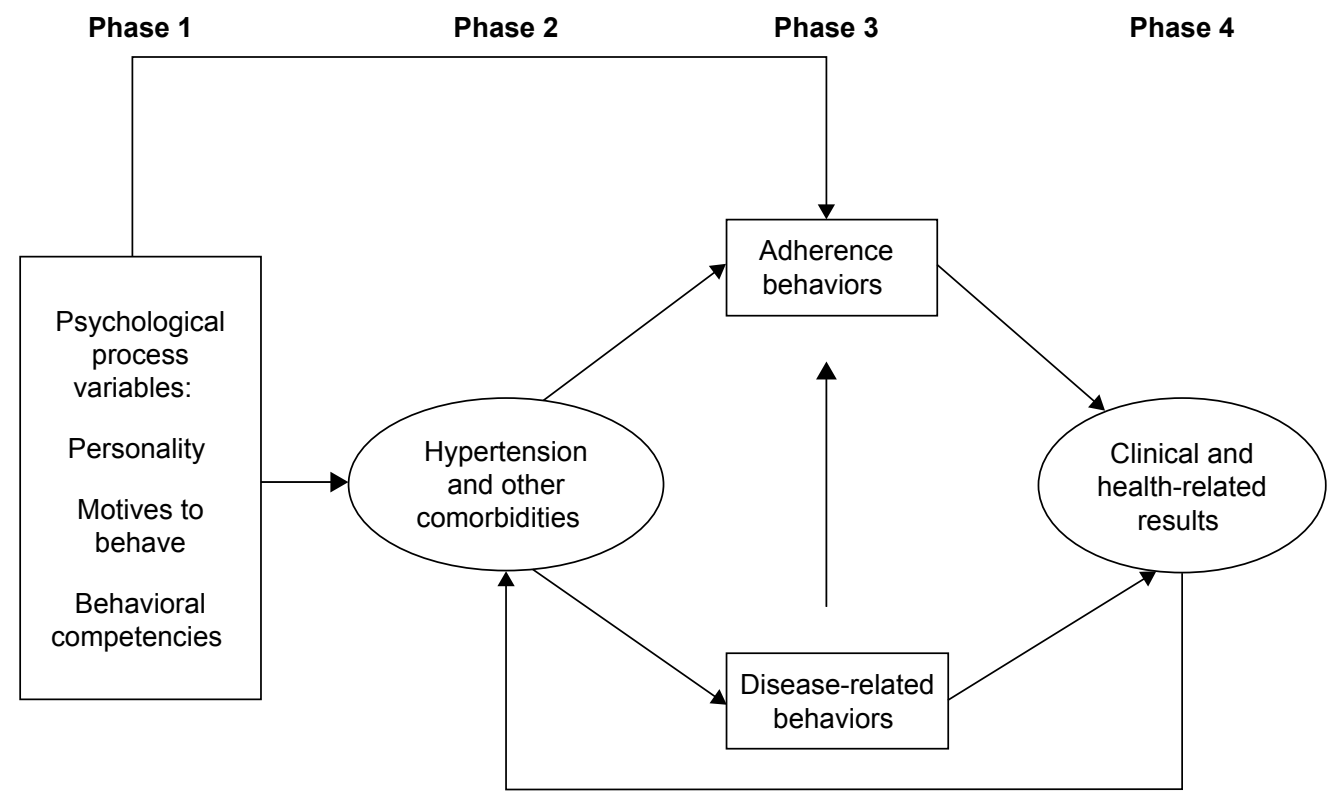

Figure I Psychological model for the research of adherence behaviors.

Note: Adapted from Piña JA, Sánchez-Sosa JJ. Psychological model for investigation of therapeutic compliance behaviors in people with HIV. Univ Psychol. 2007;6(2):399-407.'0 
Based on this background information, in this study, we aimed to test the role of psychological factors and interpersonal skills, in addition to body mass index (BMI), and the time since the disease diagnosis in the prediction of time spent on physical activity in a sample of Mexican adults with hypertension.

\section{Methods}

\section{Participants and setting}

In this study, a group of patients diagnosed with hypertension and receiving care at the Family Medicine Unit of the Institute of Health and Safety Services for State Workers (ISSSTE for its acronym in Spanish) in Ciudad Victoria, Mexico, participated. Selection of the participants was based on a non-probabilistic sampling of the intentional type. Sample size $(\mathrm{N})$ was obtained by applying the following formula: $\mathrm{N} \geq\left(Z^{2} * p * q\right) / \mathrm{EE}^{2}$, where $Z^{2}=3.84$ (squared value on abscissa corresponding to a cumulative probability of 0.95 under a standard normal distribution model), $p=$ expected prevalence (0.43), $q=1-p(0.57)$, and $\mathrm{EE}^{2}=$ squared estimation error or maximum squared difference to be tolerated between the sample prevalence and the population (true) prevalence $\left(0.072^{2}=0.0052\right)$, which results in a sample size of at least 182 participants. Those who agreed to cooperate were asked to read and sign an informed consent form, which specified the objectives of the study, emphasizing the possibility of ceasing to participate in the study when and if they decided. This study was approved by both the Ethics Committee of the Autonomous University of Tamaulipas and the Research Committee of the Institute of Health and Safety Services for State Workers, Family Medicine Unit. All procedures performed in this research were in accordance with the ethical standards of the institutional and/or national research committee and with the 1964 Helsinki declaration and its later amendments or comparable ethical standards.

\section{Instruments and measures}

Two instruments and a series of questions related to treatment-adherence and health care behaviors were used. One is a brief scale measuring stress-related situations (SRSS-12), originally designed and validated in Mexico. ${ }^{15}$ It consists of 12 questions that assess functional criteria of situations that people face from the moment they have been diagnosed with a chronic disease and require long-term treatment. The questions are based on three personality dimensions: decision-making, tolerance to ambiguity, and tolerance to frustration. An example of a decision-making question was: You are being treated and your doctor gives you instructions that you do not understand, making it difficult for you to make the right treatment decision; how do you feel? An example of a tolerance to ambiguity question was: You are receiving treatment but do not know if it will be effective and will help you control the clinical course of the disease; how do you feel? Finally, an example of a tolerance to frustration question was: You are being treated and health personnel ask you to practice different behaviors (going to appointments, doing laboratory studies, etc.), but you do not receive positive consequences (words of encouragement, feedback) from the person; how do you feel? For each question, the response options ranged from 1 to 10 : 1 representing a situation that did not generate stress reactions and 10 representing a situation that generates stress reactions.

In addition, the Duke-UNC-11 assessing social support was previously adapted and validated in Mexico. ${ }^{16}$ It includes 11 questions on social support (both emotional and trustworthy), which were answered using a 5-point Likert-type scale, where 1 represented less social support and 5 represented strong social support. An example of a question about emotional social support was: I receive visits from my family and friends; one on trustworthy social support was the following: I receive compliments and acknowledgment for doing things well in my work.

Likewise, a series of questions were used to measure different treatment-adherence and health care behaviors, which were adapted for this study from a questionnaire previously designed and validated in Mexico. ${ }^{17}$ For the purpose of this study, the following specific behaviors related to hypertension were included: taking medication, regular blood pressure measurement, clinical or laboratory studies, physical exercise, time spent on physical activity, consumption of restricted foods, as well as tobacco and/or alcohol use. In addition, we posed the specific question of whether patients spent the amount of time on physical exercise recommended by the health care personnel (30 min, at least 5 days a week), and this was answered using a 5-point Likerttype scale, defined as follows: 1 (never), equal to none day of the week; 2 (hardly spent time), between 1 and 2 days of the week; 3 (sometimes), between 3 and 4 days of the week; 4 (frequently), 5 and 6 days of the week; 5 (always), 7 days of the week. For participants who were illiterate or with primary/secondary education (who reported specific problems to understand the questions), personal assistance was provided by those in charge of applying the instruments, including reading each question.

Finally, weight and height measurements were obtained, which showed the BMI according to the categories determined by the World Health Organization (WHO): normal, 
overweight, and obese ${ }^{18}$ From clinical records, the time since the disease diagnosis was calculated in years, using persistent elevation of blood pressure levels $\geq 140 / 90 \mathrm{mmHg}^{1}$ as the standard criteria for diagnosis.

\section{Statistical analysis}

Two statistical programs were used to analyze the data: IBM SPSS for Windows version 21.0 and IBM AMOS package version 18.0. First, the assumption of multivariate normality was verified by Mardia's multivariate normality test. As the normal multivariate distribution of the data was not the case, the method of scale-free least squares (SLSs) was used, a method that can be used with ordinal variables and does not require the multivariate normality assumption. ${ }^{19}$ Calculation of standard errors of parameters and contrast of their significance was performed by the bootstrap method of bias-corrected percentiles (BCPs), extracting 2,000 samples. A confidence interval, two-tailed test, and a significance level of 0.05 were used. The strength of association showed a small effect at values of $r$ and $\beta<0.30$, medium effect with values between 0.30 and 0.499 , large between 0.50 and 0.699 , very large between 0.70 and 0.899 , and unitary $\geq 0.90 .{ }^{20}$ Seven adjustment indexes were considered: Bollen-Stine bootstrap probability with the extraction of 2,000 samples $\left(p_{B S}\right)$, relative chi square $\left(\chi^{2} / d f\right)$, standardized root mean square residual (SRMR), the Jöreskog and Sörbom's goodness of fit index (GFI) and the adjusted modality (AGFI), the Bollen's Incremental Fit Index (IFI), and Bentler-Bonett Normed Fit Index (NFI). The following values were stipulated as a close fit for the seven indexes: $p_{B S}>10, \chi^{2} / d f \leq 2, \mathrm{SRMR} \leq 0.06, \mathrm{GFI} \geq 0.95, \mathrm{AGFI} \geq 0.90$, IFI $\geq 0.95$, and NFI $\geq 0.95$, and the following values as an adequate fit: $p_{B S}>0.05, \chi^{2} / d f \leq 3$, SRMR $<0.10$, GFI $\geq 0.90$, AGFI $\geq 0.85$, IFI $\geq 0.90$, and NFI $\geq 0.90$.

The goodness of fit between the two models was considered equivalent when the quotient between the difference of their chi-square statistics and the difference between the degrees of freedom of the models was $\leq 2\left(\Delta \chi^{2} / \Delta \mathrm{gl} \leq 2\right)$ and the differences in the GFI, NFI, and IFI indexes were $\leq 0.01 .{ }^{19}$ The parsimony of the model was estimated using the James-Mulaik-Brett Parsimony Ratio (PR). Values of $\mathrm{PR} \geq 0.75$ were interpreted as high parsimony, $\geq 0.50$ as mean parsimony, $\geq 0.25$ as low parsimony, and $<0.25$ as very low parsimony. ${ }^{21}$

\section{Results}

\section{Descriptive statistics}

According to the estimated sample size, 182 participants were included in this study (for an expected prevalence of 0.43 , a $95 \%$ confidence interval, and estimation error of 0.072 ).
Among them, 139 (76.4\%) were women, 129 (76\%) were married, 82 (44.8\%) were homemakers, and $51(27.9 \%)$ were retired. The arithmetic mean of the age was 59.6 years $(\mathrm{SD}=9.9)$. According to the BMI, 54 (29.5\%) participants were categorized as overweight and 67 (36.6\%) were categorized as type 1 obese. However, practically, half of the patients performed some sort of physical activity (walking or light jogging), whereas nearly half dedicated the daily recommended time (30 min) at least 5 days a week (see Table 1).

\section{Predictors of time spent on physical activity}

Following our theoretical model, a recursive model was used to predict the practice of study behavior, which included

Table I Socio demographic, clinical, and behavioral characteristics of I 82 Mexican patients with hypertension

\begin{tabular}{|c|c|c|c|c|c|}
\hline Variables & Mean & SD & Range & $\mathbf{N}$ & $\%$ \\
\hline Age (years) & 59.6 & 9.9 & $31-83$ & & \\
\hline Time since diagnosis (years) & 9.5 & 8.8 & $1-48$ & & \\
\hline \multicolumn{6}{|l|}{ Gender } \\
\hline Male & & & & 43 & 23.6 \\
\hline Female & & & & 139 & 76.4 \\
\hline \multicolumn{6}{|l|}{ Marital status } \\
\hline Single & & & & 12 & 6.6 \\
\hline Living with a partner & & & & 132 & 72.5 \\
\hline Living without a partner & & & & 15 & 8.3 \\
\hline Widow/er & & & & 22 & 12.6 \\
\hline \multicolumn{6}{|l|}{ Educational level } \\
\hline Illiterate & & & & 28 & 15.4 \\
\hline Primary education & & & & 40 & 22.0 \\
\hline Secondary education & & & & 31 & 17.0 \\
\hline High school & & & & 35 & 19.2 \\
\hline Bachelor's degree or higher & & & & 48 & 26.4 \\
\hline \multicolumn{6}{|l|}{ Occupation } \\
\hline Homemaker & & & & 82 & 45.1 \\
\hline Employed & & & & 45 & 24.7 \\
\hline Unemployed & & & & 4 & 2.2 \\
\hline Retired & & & & 51 & 28.0 \\
\hline \multicolumn{6}{|l|}{ Body mass index (BMI) } \\
\hline Normal & & & & 16 & 8.8 \\
\hline Overweight & & & & 54 & 29.7 \\
\hline Obesity type I & & & & 67 & 36.8 \\
\hline Obesity type 2 & & & & 31 & 17.0 \\
\hline Obesity type 3 & & & & 14 & 7.7 \\
\hline \multicolumn{6}{|l|}{ Performs physical activity } \\
\hline Never & & & & 22 & 12.1 \\
\hline Hardly ever & & & & 19 & 10.4 \\
\hline Sometimes & & & & 46 & 25.3 \\
\hline Frequently & & & & 29 & 15.9 \\
\hline Always & & & & 66 & 36.3 \\
\hline \multicolumn{6}{|l|}{ Physical activity (time spent) } \\
\hline Never & & & & 23 & 12.6 \\
\hline Hardly ever & & & & 18 & 9.9 \\
\hline Sometimes & & & & 44 & 24.2 \\
\hline Frequently & & & & 25 & 13.7 \\
\hline Always & & & & 72 & 39.6 \\
\hline
\end{tabular}

Abbreviation: SD, standard deviation. 


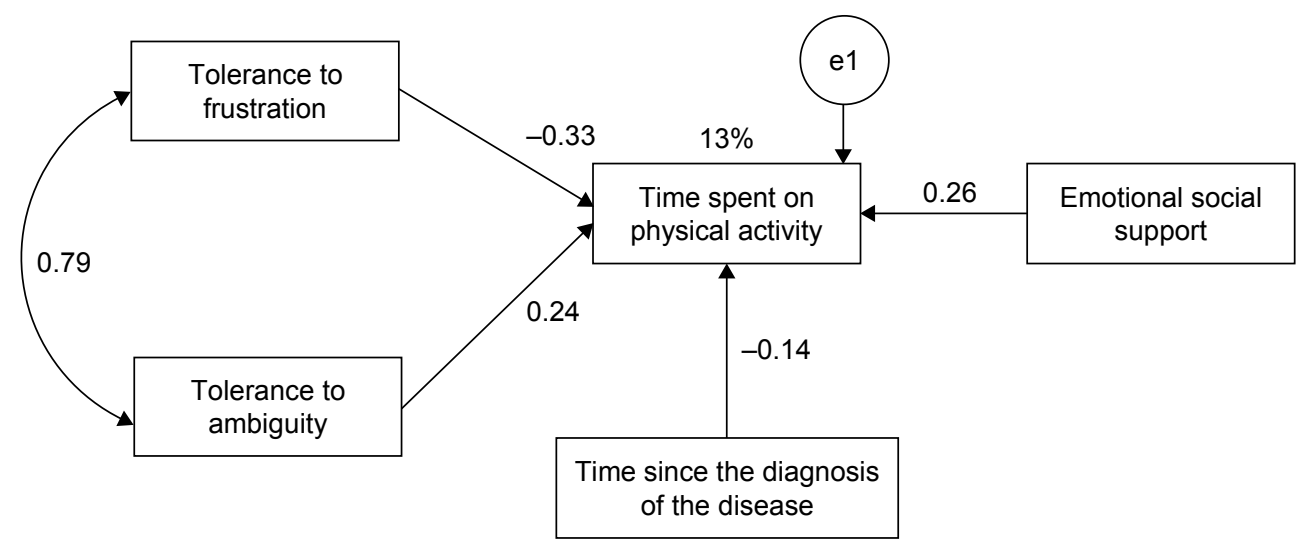

Figure 2 Revised model of the study behavior: time spent on physical activity.

seven exogenous variables: three related to personality (decision-making, tolerance to ambiguity, and tolerance to frustration), two related to perceived social support (emotional and trustworthy), one related to BMI, and finally, one related to time since the diagnosis of hypertension. In theory, the multivariate distribution was not adjusted to a normal distribution (Mardia's multivariate asymmetry test: $\chi^{2}=62.12$, $p<0.001$; Mardia's multivariate kurtosis test: $Z=53.12$, $p<0.001$, with the standardized value of the multivariate kurtosis of Mardia $=4.671$ ); therefore, the SLS method was chosen. The discrepancy function was estimated by SLS converged in seven iterations (Min $[\mathrm{FD}]$ or $\chi^{2}=25.23$ ). The solution was found to be admissible, but three variables out of seven that predict the performance of recommended physical activity were not found to be significant by BCP: decisionmaking ( $\beta=-151[-32,0.02], p=0.091)$, trustworthy social support $(\beta=-0.04[-18,0.280], p=0.69)$, and BMI $(\beta=-0.13$ $[-0.27,0.01], p=0.070)$.

After eliminating the three non-significant prediction variables one by one, the model was reestimated. The discrepancy function estimated by SLS converged in six iterations (Min [FD] or $\chi^{2}=7.53$ ). The solution was found to be admissible, and all parameters were found to be significant by BCP. Regarding recommended physical activity, the effect of tolerance to frustration on behavior was found to be negative and moderate in size ( $\beta=-0.33[-0.55,-10], p=0.004)$; meanwhile, tolerance to ambiguity $(\beta=0.24[0.00,0.45], p=0.049)$ and emotional social support $(\beta=0.26[0.13,0.40], p=0.001)$ were found to be positive and small in size; likewise, the time since the disease diagnosis was found to be negative and small in size ( $\beta=-0.14[-0.27,-0.00], p=0.045)$. Therefore, lower tolerance to frustration, greater tolerance to ambiguity, greater perceived (emotional) social support, and shorter time since diagnosis predicted overall study behavior, and the percentage of explained variance was found to be $13.3 \%$.

The model had a good fit for five of the seven indices $\left(p_{B S}=0.235, \chi^{2} / d f=1.519\right.$, GFI $=0.987$, AGFI $=0.962$, and IFI $=0.981)$ and adequate for the remaining two indexes (NFI $=0.946$ and SRMR $=0.053$ ). Its parsimony was found to be average ( $R P=0.50$ ). The correlation between tolerance to frustration and tolerance to ambiguity was found to be positive and high ( $r=0.79$ [0.70, 0.85], $p=0.001)$, with a shared variance of $62.4 \%$ so that both could be taken as a single variable (see Figure 2 and Table 2). However, when combined in a single variable (sum of scores in both variables), the effect was not found to be significant ( $\beta=-0.09$ $[-0.24,0.04], p=0.185)$, because the effect of each of them was opposite (positive and negative), which is the reason why

Table 2 Parameters of the modified model of the study behavior: time spent on physical activity (M2)

\begin{tabular}{|c|c|c|c|c|c|c|c|}
\hline \multicolumn{3}{|c|}{$\begin{array}{l}\text { Structural pathways } \rightarrow \\
\text { and correlations } \leftrightarrow\end{array}$} & \multirow{2}{*}{$\begin{array}{l}\text { SP }(95 \% \mathrm{Cl}) \\
0.25(0.00,0.45)\end{array}$} & \multirow{2}{*}{$\begin{array}{l}p \text {-value } \\
0.049\end{array}$} & \multirow{2}{*}{$\begin{array}{l}\text { Variables } \\
\text { S-TA }\end{array}$} & \multirow{2}{*}{$\begin{array}{l}S^{2}(95 \% \mathrm{Cl}) \\
67.82(56.64,78.66)\end{array}$} & \multirow{2}{*}{$\frac{p \text {-value }}{}$} \\
\hline S-TA & $\rightarrow$ & $\mathrm{PAB}$ & & & & & \\
\hline S-TF & $\rightarrow$ & $\mathrm{PAB}$ & $-0.33(-0.55,-0.10)$ & 0.004 & S-TF & $205.63(166.26,246.56)$ & 0.001 \\
\hline TDx & $\rightarrow$ & $\mathrm{PAB}$ & $-0.14(-0.27,-0.00)$ & 0.045 & TDx & $77.76(57.21,103.11)$ & 0.001 \\
\hline ESS & $\rightarrow$ & $\mathrm{PAB}$ & $0.27(0.13,0.40)$ & 0.001 & ESS & $30.38(24.40,36.97)$ & 0.001 \\
\hline S-TA & $\leftrightarrow$ & S-TF & $0.79(0.70,0.85)$ & 0.001 & el & $1.72(1.48,2.07)$ & $<0.001$ \\
\hline
\end{tabular}

Abbreviations: SP, standardized parameter; $S^{2}$, exogenous variables variance; PAB, physical activity behavior; S-TF, stress related to tolerance to frustration; S-TA, stress related to tolerance to ambiguity; ESS, emotional social support; TDx, time since diagnosis; el, structural error. 
the model requires considering them as individual variables, despite high shared variance.

\section{Discussion}

By eliminating decision-making in the second path analysis, it was found that tolerance to frustration and tolerance to ambiguity influenced the study behavior in different ways; that is, even though the interaction between the two variables was high ( $r=0.79 ; p=0.001)$, the first one operated in a negative direction and the second in a positive direction. This means that not receiving or postponing positive consequences (a compliment, congratulations or positive feedback from health personnel) did not encourage affective or emotional responses in patients that openly competed with the practice of the study behavior. Regarding tolerance to ambiguity, a high score in this area is related to the fact that patients do not effectively relate the positive/negative effects on their disease control in the medium or long term to perform physical exercise..$^{22,23}$

If personality is a historical variable and allows us to account for how a person behaves in the present and the future, as they have done in the past, then social support is an interpersonal variable and contextual in nature. We point out this significant difference and the way each variable operates, because to begin with, low scores were expected in the two dimensions of personality and high scores were expected in social support, which did not occur. That is, if a patient does not receive positive consequences when engaging in a behavior (performing physical activity frequently or of long duration), what is found here suggests that it is actually the people in their immediate social circle to whom they will go for these positive consequences. This finding is consistent with the results of other studies of samples of HIV-positive people, in which it has been shown that the personality variable usually interacts with other variables such as motives and behavioral competencies rather than with contextual interpersonal variables, such as social support. ${ }^{12,13}$

In addition, it is important to note that the effect of BMI on study behavior followed its expected direction, even when it was not significant. At first, being overweight and obese may be factors that inhibit exercise, either because of lack of habit, or because patients are in worse physical shape, or because of the discomfort caused when performing physical activity. ${ }^{24-26}$ Likewise, the expectation was confirmed that shorter the time since the diagnosis of a chronic disease, the more people are motivated to follow the recommendations of health care personnel, especially when from this diagnosis, a person evaluates the possibility of managing the impact of the disease, and its possible effects in psychological terms, which are included among the disease-related behaviors in our theoretical model..$^{27,28}$

Having said that, promoting the practice of physical exercise in people diagnosed with hypertension requires explicit consideration of the set of psychological, interpersonal, anthropometric, and clinical variables that when interacting with each other to a lesser or greater extent make them more or less likely to follow the recommendations of health care personnel. Taking this set of variables into account will surely mean that the design, implementation, and evaluation of any intervention will be performed on interdisciplinary terms, among medical personnel, nurses, social workers, psychologists, nutritionists, and so on, ${ }^{29,30}$ as a necessary condition in order to ensure effective integration of proposals that can be systematically evaluated.

Despite the results obtained in this study, it is important to consider the following limitations. First, since it was conducted using non-probabilistic sampling of the intentional type, the results do not constitute estimates at the population level, but instead must be treated as hypotheses or expectations for future studies. Second, the sample size was somewhat limited $(<200)$; therefore, we chose to use the path analysis and Pearson's correlations for data analysis, since they yield better results with a sample of 182 participants, as was the case in this study; with this size, we reached $\sim 10$ participants per estimated parameter in the initial model (182:19) and about 18 participants per estimated parameter in the final model (182:10). Third, because other psychological variables of the theoretical model (motives and behavioral competencies) were not measured, it was impossible to establish the interaction between the two variables with those of personality and social support, fundamentally, to determine if the motives to do things and knowledge of how to do them influence the practice of treatment adherence and health care behaviors. Finally, it is important to note that in this sample, the highest percentage of participants were $\geq 20$ years, considering, they were female; this may be due to three phenomena that are being observed in the state of Tamaulipas. First, according to the data found in the National Health and Nutrition Survey 2012, the problem of hypertension in people under 20 years of age is not epidemiologically relevant. Second, in the use of health services, the differences between men and women are important in terms of percentage, including the prevention of hypertension in both general population and those categorized by age (eg, in the age group of 20-39 years, the detection of hypertension was $21.2 \%$ in men and $26.1 \%$ in women, whereas in the age 
group of 40-59 years, it was $29.1 \%$ and $37.2 \%$, respectively). Third, we must bear in mind that the prevalence of hypertension was $13.6 \%$ in men and $23.2 \%$ in women, a difference that is more accentuated in the age groups of 40-59 years, as well as in the age group of $\geq 60$ years. ${ }^{31}$ Therefore, and considering these limitations, it will be necessary to design a new study that contemplates not only a highly representative sample of people diagnosed with hypertension in the state of Tamaulipas but also to explore to what extent the differential weight of the psychological (personality, motives, and behavioral competencies), interpersonal (social support), and clinical variables of the model can be affected by gender and by different groups of age.

\section{Conclusion}

In conclusion, the recursive model that predicts whether a patient will perform the recommended physical activity showed a good fit to the data, a medium-sized overall effect, and mean parsimony. Lower tolerance to frustration with treatment, greater tolerance to ambiguity, greater emotional social support, and less time since diagnosis all make patients more likely to follow the recommendations made by the health personnel about how much time they should spend for physical activity. One strong point of this study was the use of analysis techniques, which were suitable to the ordinal nature of the endogenous variable and to the lack of multivariate normality. Such techniques include SLS to minimize discrepancy function, BCP to calculate standard errors and the significance of the parameters, and the Bollen-Stine bootstrap procedure to test overall goodness of fit.

\section{Disclosure}

The authors report no conflicts of interest in this work.

\section{References}

1. Campos-Nonato I, Hernández-Barrera L, Roja-Martínez R, PedrozaTobías A, Medina-García C, Barquera-Cervera S. Hypertension: prevalence, early diagnosis, control and trends in Mexican adults. Salud Publica Mex. 2013;55(Suppl 2):S144-S150. Spanish [with English abstract].

2. Everson-Rose SA, Lewis TT. Psychological factors and cardiovascular diseases. Annu Rev Public Health. 2005;26:469-500.

3. DiMatteo MR, Haskard-Zolnierek KB, Martin LR. Improving patient adherence: a three-factor model to guide practice. Health Psychol Rev. 2012;6(1):74-91.

4. Ezzati M, Riboli E. Behavioral and dietary risk factors for noncommunicable diseases. $N$ Engl J Med. 2013;369(10):954-964.

5. Cordero A, Masiá MD, Galve E. Physical exercise and health. Rev Esp Cardiol (Engl Ed). 2014;67(9):748-753. Spanish [with English abstract].

6. Hegde SM, Solomon SD. Influence of physical activity on hypertension and cardiac structure and function. Curr Hypertens Rep. 2015; 17(10):77-84.
7. Bauman AE, Reis RS, Sallis JF, Wells JC, Loss RJ, Martin BW; Lancet Physical Activity Series Working Group. Correlates of physical activity: why are some people physically active and others not? Lancet. 2012; 380(9838):258-271.

8. Mansyur CL, Pavlik VN, Hyman DJ, Taylor WC, Goodrick GK. Selfefficacy and barriers to multiple behavior change in low-income African Americans with hypertension. J Behav Med. 2013;36(1):75-85.

9. Flynn SJ, Ameling JM, Hill-Briggs F, et al. Facilitators and barriers to hypertension self-management in urban African Americans: perspective of patients and family members. Patient Pref Adh. 2013;7: 741-749.

10. Piña JA, Sánchez-Sosa JJ. Psychological model for investigation of therapeutic compliance behaviors in people with HIV. Univ Psychol. 2007;6(2):399-407. Spanish [with English abstract].

11. Ribes E. La personalidad como organización de los estilos interactivos [Personality as the organization of interactive styles]. Rev Mex Psicol. 2009;26(2):145-161. Spanish [with English abstract].

12. González MT, Piña JA. Motivos, apoyo social y comportamientos de adhesión en personas con VIH: modelamiento con ecuaciones estructurales [Motives, social support and adherence behaviors in HIVpatients: structural equation modeling]. Univ Psychol. 2011;10(2):399409. Spanish [with English abstract].

13. Rosas MA, González MT. Social support and motives: their influence on treatment adherence and biomarkers among HIV patients from Michoacan, Mexico. Int J Hisp Psychol. 2012;5(2):167-180.

14. Piña JA, Ybarra JL, Méndez J. Variables psicológicas y enfermedades crónicas: su peso diferencial depende de la enfermedad, el tiempo transcurrido desde el diagnóstico y los tipos de tratamiento [Psychological variables and chronic diseases: their importance depends on the disease, time since diagnosis, and modality of treatment]. In: Vargas MA, Galán S, Camacho E,Zárate A, editors. Avancesy perspectivas de la psicología en los albores del siglo XXI. Guadalajara: Orgánica Editores; 2016. Spanish.

15. Piña JA, Valencia MA, Mungaray K, Corrales AE. Validación de una escala breve que mide situaciones vinculadas con estrés en personas VIH positivas [Validation of a short scale that measures stress related events in HIV positive patients]. Ter Psicol. 2006;24(1):15-21. Spanish [with English abstract].

16. Piña JA, Rivera BM, Corrales AE. Validation of the functional social support questionnaire in seropositive persons to the HIV from the northwest of Mexico. Cienc Enferm. 2007;13(2):53-63. Spanish [with English abstract].

17. Piña JA, Corrales AE, Mungaray K, Valencia MA. Instrumento para la evaluación de variables psicológicas y conductas de adhesión al tratamiento en personas que son seropositivas al VIH (VPAD-24) [Instrument for measuring psychological variables and adherence to treatment behavior in persons who are seropositive for HIV (VPAD-24)]. Rev Panam Salud Publica. 2006;19(4):217-228. Spanish [with English abstract].

18. World Health Organization. Obesity: preventing and managing the global epidemic. Report of a WHO Consultation. WHO Technical Report Series 894. Geneva: World Health Organization, 2000. Available from: http://whqlibdoc.who.int/trs/WHO_TRS_894.pdf. Accessed January 10, 2017.

19. Byrne BM. Structural Equation Modeling with Amos: Basic Concepts, Applications, and Programming. 3rd ed. New York: Routledge; 2016.

20. Ellis PD. The Essential Guide to Effect Sizes: An Introduction to Statistical Power, Meta-Analysis and the Interpretation of Research Results. Cambridge, UK: Cambridge University Press; 2010.

21. Preacher KJ. Quantifying parsimony in structural equation modeling. Mult Behav Res. 2006;41(3):227-259.

22. Sanz J, García-Vera MP, Espinosa R, Fortún M, Magán AI, Segura J. Psychological factors associated with poor hypertension control: differences in personality and stress between patients with controlled and uncontrolled hypertension. Psychol Rep. 2010;107(3):923-938.

23. Edwards SD. Case study on hypertension, physical exercise and psychophysiological coherence feedback. Afr J Phys Activ Health Sci. 2016;22(2:2):514-524. 
24. Yang L, Yan J, Tang X, Xu X, Yu W, Wu H. Prevalence, awareness, treatment, control and risk factors associated with hypertension among adults in Southern China, 2013. PLoS One. 2016;11(1): e0146181.

25. Gascón Cánovas JJ, Saturno Hernández PJ, Llor Esteban B; Grupo de Investigación del Proyecto EMCA sobre Evaluación y Mejora de la Adhesión Terapéutica en la Hipertensión. Evaluation and improvement of therapy adherence of hypertensive patients. Aten Primaria. 2001; 28(9):615-619. Spanish [with English abstract].

26. Spencer RM, Heidecker B, Ganz P. Behavioral cardiovascular risks factors - effect of physical activity and cardiorespiratory fitness on cardiovascular outcomes. Circulation J. 2016;80(1):34-43.

27. Bluethmann SM, Mariotto AB, Rowland JH. Anticipating the "Silver Tsunami": prevalence trajectories and comorbidity burden among older cancer survivors in the United States. Cancer Epidemiol Biomarkers Prev. 2016;25(7):1029-1036.
28. Flores-Valdez I, León-Santos M, Vera-Hernández E, HernándezPozo R. Psychological interventions on stress management and reduction for hypertensive patients: a review of their effectiveness. Psychol Av Disc. 2013;7(2):25-44. Spanish [with English abstract].

29. Sparling PB, Howard BJ, Dunston DW, Owen N. Recommendations for physical activity in older adults. BMJ. 2015;350:h100.

30. Thorton JS, Frémont P, Khan K, et al. Physical activity prescription: a critical opportunity to address a modifiable risk factor for the prevention and management of chronic disease: a position statement by the Canadian Academy of Sport and Exercise Medicine. Br J Sports Med. 2016;50(18):1109-1114.

31. Gutiérrez JP, Rivera J, Shamah T, Oropeza C, Hernández-Ávila M. Encuesta Nacional de Salud y Nutrición. Resultados por entidad federativa 2012 [National Health and Nutrition Survey. Results by State 2012]. Cuernavaca: Instituto Nacional de Salud Pública; 2013. Spanish.

\section{Publish your work in this journal}

Patient Preference and Adherence is an international, peer-reviewed, open access journal that focuses on the growing importance of patient preference and adherence throughout the therapeutic continuum. Patient satisfaction, acceptability, quality of life, compliance, persistence and their role in developing new therapeutic modalities and compounds to optimize clinical outcomes for existing disease states are major areas of interest for the journal. This journal has been accepted for indexing on PubMed Central. The manuscript management system is completely online and includes a very quick and fair peer-review system, which is all easy to use. Visit http://www dovepress.com/testimonials.php to read real quotes from published authors. 